\title{
ECOBRICK Sebagai Pemanfaatan Sampah Plastik di Laboratorium Biologi dan Foodcourt Universtias Negeri Yogyakarta
}

\section{ECOBRICK as The Utilization of Plastic in Biology Laboratory and Foodcourt Yogyakarta State University}

Aditia Pramudia Sunandar ${ }^{1}$, Fiki Zida Farhana ${ }^{2}$ dan Rizki Qonitati Chandra Chahyani ${ }^{3}$

Jurusan Pendidikan Biologi, FMIPA, Universitas Negeri Yogyakarta ${ }^{1,2,3}$, Email: laditiapramudia.2017@student.uny.ac.id

\begin{abstract}
Abstrak
Produksi sampah plastik saat ini sudah tidak terbendung lagi. Masyarakat semakin sulit terlepas dari penggunaan plastik. Hal tersebut tentu saja berdampak pada tercemarnya lingkungan karena limbah plastik yang menumpuk dan memerlukan waktu yang cukup lama untuk terurai secara alami. Terlebih lagi karena penggunaan plastik hampir tidak bisa dikendalikan. Plastik juga menjadikan suhu udara menjadi lebih panas dari ke hari, karena sifat polimernya yang tidak berpori. Pada saat ini, sebagian besar produk yang diproduksi tanpa memikirkan ke mana mereka akan pergi ketika dikonsumsi. .Di lingkungan Universitas Negeri Yogyakarta sampah plastik sangat mudah ditemukan di lingkungan Foodcourt dan Laboratorium Biologi. Dalam upaya mengurangi limbah plastik peneliti berinisiatif untuk membuat ecobrick sebagai pemanfaatan dan daur ulang limbah plastik. Ecobrick adalah salah satu usaha kreatif bagi penanganan sampah plastik. Fungsinya bukan untuk menghancurkan sampah plastik, melainkan untuk memperpanjang usia plastik-plastik tersebut dan mengolahnya menjadi sesuatu yang berguna, yang bisa dipergunakan bagi kepentingan manusia pada umumnya..Dengan cara mengolah kembali limbah botol plastik menjadi barang yang bisa digunakan kembali seperti tempat sampah, kursi, dan meja serta mendukung penyadaran terhadap mahasiswa biologi untuk membuang sampah pada tempatnya sesuai arahan. Hasil penelitian ditunjukkan dengan selalu penuhnya tiga kardus sampah yang disediakan di laboratorium Biologi setiap seminggu dan mencapai angka 60\%. Pemanfaata ecobrick membutuhkan bahan dasar yang cukup banyak dan peranan setiap pihak karena masih menggunakan tenaga manual namun memiliki hasil yang positif dalam mengurangi sampah plastik dilingkungan masyarakat.
\end{abstract}

Kata kunci: Ecobrick, Sampah Plastik, Daur Ulang.

\begin{abstract}
Plastic waste production is now unstoppable. The community is increasingly difficult regardless of the use of plastic. This of course has an impact on the pollution of the environment because plastic waste accumulates and requires a long time to decompose naturally. Plastics also make the air temperature hotter day by day, due to its non-porous polymeric properties. At the moment, most products are produced without thinking of where they are going when consumed.In the State University of Yogyakarta plastic waste is very easily found in the Foodcourt and Biology Laboratory area. In an effort to reduce plastic waste researchers took the initiative to make ecobrick as the utilization and recycling of plastic waste. Ecobrick is one of the creative endeavors for handling plastic waste. Its function is not to destroy plastic waste, but to extend the life of these plastics and process them into something useful, which can be used for the benefit of humans in general. By reprocessing plastic bottle waste into items that can be reused, such as bins, chairs, and
\end{abstract}


tables, and support awareness of biology students to dispose of garbage in its place according to directions. The results of the study are always indicated by the full three boxes of garbage provided in the Biology laboratory every week and reaching 60\%. Utilizing ecobrick requires a lot of basic ingredients and the role of each party because it still uses manual labor but has positive results in reducing plastic waste in the community.

Key words : Ecobrick, Plastic waste, Recycle.

\section{PENDAHULUAN}

Permasalahan gobal yang hingga kini belum terselesaikan adalah volume sampah yang jumlahnya terus meningkat seirinh dengan bertambhanya jumlah penduduk (Sari, 2018).Permasalahan global sehubungan dengan masa depan perkotaan beberapa diantaranya adalah permasalahan lingkungan. Wati dalam (Bengkulah, 2017) menyebutkan ada dua jenis faktor yang menyebabkan kerusakan lingkungan hidup, dua jenis tersebut yaitu : 1. Kerusakan lingkungan hidup yang disebabkan oleh faktor alam, bentuk bencana alam yang menimbulkan dampak rusaknya lingkungan hidup, 2. Kerusakan lingkungan hidup yang disebabkan oleh faktor manusia. Manusia sebagai makhluk hidup yang menguasai lingkungan hidup di bumi memiliki peran besar dalam menentukan kelestarian lingkungan hidup.

Plastic merupakan salah satu faktor dari sekian banyak faktor penyebab kerusakan alam disebabkan oleh faktor manusia. Hamper setiap kehidupan mulai dari bahan pembungkus makanan hingga perlatan rumah tangga rata-rata menggunakan plastic. Merupakan bahan yang sangat popular dan banyak digunakan saat ini. Permasalahan paling utama adalah limbah platik tidak bisa terurai secara alami, jikalau pun terurai membutuhkan waktu yang sangat lama bahkan ribuan tahun untuk menguraikan plastic di alam. Plastic tidak akan hilang meskipun dibakar hanya akan berubah menjadi mikroplastik. Bahkan mikroplastik bisa berbahaya apabila tercampur dengan tanah dan air karena akan menjadi racun jika tercampur di air dan masuk ke dalam tubuh manusia.
Sedangkan untuk pemanfaatan limbah plastic tetapi dengan pengolahan yang lebih kompleks seperti menggunakan analisis kimia pernah dilakukan (Wahyudi, E., Zultiniar, \& E, 2016). Sampah plastik memiliki dampak buruk bagi lingkungan apabila tidak diolah lebih lanjut penelitiannya dilakukan untuk mengkonversi sampah plastik menjadi bahan bakar minyak menggunakan katalis sintetis yang disintesis dari abu terbang batubara yang selanjutnya dikarakterisasi menggunakan XRD.

Plastic sendiri adalah bahan recycle atau bahan daur ulang yang sebenarnya ada banyak cara pengolahan-pengolahannya. Sayangnya di era sekarang ini kesadaran masyarakat terhadap lingkungan bisa dikatakan cukup rendah, masyarakat cenderung tak acuh terhadap limbah plastic yang ada disekitarnya..Sampah plastic yang ada di Foodcourt UNY merupakan masalah yang ada di lingkungan kampus. Sampah yang ada di Foodcourt UNY tidak hanya berasal dari penjual saja, bahkan konsumen itu sendiri sehingga menimbulkan ketidaknyamanan saat beraktivitas. Selain itu, sampah plastic di Laboratorium Biologi FMIPA UNY juga cukup mengganggu. Sampah plastic yang sebagian besar berasal dari bungkus makanan dan minuman.

Sumber sampah terbanyak adalah berasal dari pemukiman, komposisinya berupa $75 \%$ terdiri dari sampah organik dan hanya 25\% sampah anorganik.. Sampah anorganik sangat sulit didegradasi bahkan tidak dapat didegradasi sama sekali oleh alam, oleh karena itu diperlukan suatu lahan yang sangat luas untuk mengimbangi produksi sampah jenis ini. Karena potensinya yang cukup besar, alangkah lebih 
baik untuk memanfaatkan sampah plastik ini menjadi produk dan jasa kreatif dalam rangka mengelola sampah plastik dengan baik, sehingga plastik benar-benar mendukung kehidupan kita. Sebagai produk kreatif, karya kreasi sampah plastik. memiliki nilai komersial yang menjanjikan. Produk ini memiliki daya jual yang dapat menghasilkan keuntungan. Secara umum, bisnis ini terbagi dalam dua jenis, yaitu produk dan jasa (Putra, H, P., \& Y, 2010).

Salah satu inovasi daur ulang sampah plastic yang tim kami kerjakan adalah dengan membuat ecobrick menjadi tempat sampah. Tidak hanya sebagai salah satu cara pengolahan atau daur ulang plastic, apabila penggunaan ecobrick terus dilakukan maka limbah plastic akan dapat di olah dan memiliki nilai ekonomis. Ecobrick yang tim kami kerjakan diharapkan dapat menjadi contoh bagi yang lainnya untuk mengurangi dampak buruk sampah plastic dan menjadikan sampah plastic sesuatu yang bisa digunakan kembali.

Tujuan dari PPM ini adalah :

1. Melatih mahasiswa untuk memanfaatkan bahan yang tidak bermanfaat menjadi lebih bernilai di Lingkungan Foodcourt dan Laboratorium Biologi UNY.

2. Meningkatkan kesadaran mahasiswa dengan membuang sampah sesuai jenis dan tempatnya dengan arahan.

3. Luaran berupa laporan hasil pengamatan kesadaran mahasiswa dan produk berupa Ecobrick.

\section{Solusi/Teknologi}

Menurut (Sampah Plastik Jenis, dan Menjadi Bahan Bakar Minyak dan Karakteristiknya Untoro Budi Surono, \& Ismanto, 2016)plastik memiliki keunggulan dibanding material lain, yaitu kuat, ringan, flesibel, tahan karat, mudah diberi warna dan dibentuk serta tidak mudah pecah. Hal ini mendukung maraknya penggunaan plastik oleh masyarakat dan mahasiswa dalam kehidupan sehari-hari. Salah satu tempat yang menghasilkan sampah plastik dalam jumlah yang besar adalah Food Court. Di Universitas Negeri Yogyakarta, Food Court adalah pusat tempat mahasiswa beristirahat dan makan siang. Hal ini didukung oleh tempatnya yang luas dan strategis. Food Court UNY memiliki 15 tempat makan yang mengelilingi pendopo utama. Dengan banyaknya penjual dan tempat makan yang cukup luas, sayangnya tempat sampah yang disediakan tidak banyak. Jumlah tempat sampah di tempat ini hanya 12 buah dan beberapa diantaranya memiliki kondisi yang kurang baik. Karena sedikitnya jumlah tempat sampah dan tidak mencakup seluruh tempat yang ada, mengakibatkan banyaknya penumpukan sampah di berbagai tempat. Sampah yang ada di Food Court UNY rata-rata ialah sampah plastic sekali pakai yang sering ditinggalkan begitu saja oleh konsumen.

Ecobrick merupakan salah satu metode yang dapat digunakan untuk meminimalisir permasalahan sampah di lingkungan sekitar kita, khususnya di lingkungan perkuliahan. Ecobrick adalah botol plastic yang diisi dengan sampah plastik bekas, bersih dan kering pada kepadatan tertentu yang dapat digunakan sebagai bahan bangunan dan dapat digunakan berulang kali. Sampah yang digunakan adalah sampah plastik yang kering dan bersih. Proses pengumpulan sampah dilakukan dengan pengadaan tempat sampah khusus plastik yang diletakkan di tempat-tempat yang sering dilalui mahasiswa. Cara pembuatan Ecobrick adalah dengan memadatkan sampah plastic non-biodegradable (tidak dapat terurai secara proses biologis) ke dalam botol plastic bekas pakai. Hal ini dapat dilakukan untuk mencegah sampah plastik agar tidak mencemari lingkungan serta menghindari daur ulang yang dalam prosesnya kurang efektif dan mencemari lingkungan karena persiapan dan pengetahuan yang kurang matang. Contoh proses daur ulang plastic yang mencemari lingkungan adalah pembakaran yang dilakukan dibawah suhu 
800C yang tergolong kedalam pembakaran tidak sempurna. Pembakaran ini dapat membentuk dioksin, yaitu senyawa yang dapat memicu hepatitis, kanker, gangguan sistem saraf dan pembengkakan hati (Sirait, 2009).

Ecobrick yang telah dipadatkan dapat dimanfaatkan untuk banyak hal, seperti disusun dan diperkuat dengan semen sehingga dapat membangun ruang-ruang hijau bagi masyarakat. Selain itu, dengan kepadatan yang baik, Ecobrick dapat dibentuk dan digunakan sebagai furniture didalam rumah seperti meja, kursi dan tempat sampah.

Pembuatan Ecobrick di lingkungan sekitar dapat menjadi solusi penumpukan sampah yang sering terjadi, salah satunya di lingkungan perkuliahan. Dengan pengelolaan dan pemilihan sampah yang baik, dapat dibuat Ecobrick yang ramah lingkungan dan digunakan sebagai bahan dasar untuk membuat tempat sampah yang dapat diletakkan di setiap sudut gedung perkuliahan.

Untuk mendukung pembuatan ecobrick ini diciptakan pula gerakan "\#GaMakePlastik" yang akan dikampanyekan melalui media social. Gerakan ini bertujuan untuk menghimbau masyarakat untuk tidak selalu bergantung pada plastik. Melalui tagar ini, diharapkan kesadaran masyarakat akan bahaya penggunaan plastik sekali pakai terus meningkat, sehingga jumlah plastic di lingkungan kita tidak semakin banyak. Penggunaan tagar ini akan terus diramaikan seiring berjalannya waktu sehingga ikut melancarkan dan mempopulerkan pembuatan Ecobrick.

Ecobrick menjadi aternatif dalam penyampaian pendidikan linkungan kepada masyarakat. Karena pendidikan lingkungan merupakan tanggung jawab segenap masyarakat, namun peran mahasiswa dalam menjaga merupakan pihak yang pertama dan utama. Kecintaan terhadap lingkungan dan edukasinya pada masyarakat ini akan membentuk karakter yang cinta alam.

\section{Hasil dan Diskusi}

Berdasarkan penelitian dan observasi yang telah dilakukan, banyaknya tempat sampah yang berada di Laboratorium Biologi FMIPA dan Foodcourt UNY tidak sebanding dengan banyaknya sampah yang dihasilkan serta kesadaran dalam membuang sampah sesuai anjuran.

Menurut (Saldana, 2011), observasi dapat juga berfungsi sebagai pendahuluan sebelum melakukan wawancara. Kemudian, metode wawancara pun dilakukan guna menggali permasalahan-permasalahan yang dihadapi serta memberikan informasi yang dapat mendukung penelitian, seperti proses produksi ecobrick, kendala yang dihadapi, penjualan ecobrick selama ini, dan lain-lain.

Area Foodcourt UNY memiliki 12 tempat sampah, hal ini sepertinya tidak sebanding dengan jumlah rumah makan yang ada di Foodcourt UNY yaitu sebanyak 10 rumah makan. Jika dianalogikan 10 tempat makan memproduksi lebih dari 50 porsi perhari maka jumlah sampah yang dihasilkan bisa melebihi tempat sampah yang ada. Jumlah sampah yang ada di Foodcourt UNY tidak hanya berasal dari sampah yang dihasilkan oleh rumah makan saja namun juga berasal dari konsumen itu sendiri. Sampah dari konsumen yang banyak ditemukan adalah botol plastik yang memang menjadi kebutuhan sehari-hari dari konsumen itu sendiri.

Konsumen di Foodcourt UNY bukan hanya berasal dari mahasiswa saja namun juga berasal dari masyarakat umum dan pengunjung. Foodcourt UNY yang memiliki letak strategis ini berada dekat dengan pusat aktivitas di Universitas Negeri Yogyakarta yaitu Museum Pendidikan Indonesia, Digital Library, Perpustakaan Pusat, Rektorat UNY, Fakultas Ilmu Pendidikan, Fakultas Ekonomi, Fakultas Ilmu Sosial, Fakultas Matematika dan Ilmu Pengetahuan Alam, Masjid Mujahidin, dan Program Pascasarjana. Banyak dari mahasiswa asal fakultas-fakultas tersebut yang memilih Foodcourt UNY sebagai tempat untuk istirahat dan makan di siang hari apalagi 
menu yang ada di Foodcourt UNY terkesan lebih variatif. Inilah yang menjadi alasan mengapa sampah di Foodcourt UNY begitu banyak ketimbang sampah di tempat makan lain di Universitas Negeri Yogyakarta. Keadaan ini tidak didukung dengan pengelolaan Foodcourt yang belum baik ditunjukkan dengan pengelola yang jarang sekali hadir, kemudian petugas kebersihan yang hanya bekerja pada hari kerja mulai dari jam 05.00-07.00 WIB dan 15.00-16.00 WIB sedangkan pada hari kerja tidak ada pengelolaan kebersihan. Hal inilah yang mengakibatkan keluhan dari pengelola rumah makan yaitu bau yang muncul ketika hari seninnya tiba.

Plastik terdiri dari berbagai jenis yaitu PET (PolyEtylene Terephthalate), PP (Polypropylene), PVC (Polyvinyl Chloride), PS (Poly Styrene), PTFE-Teflon (Polytetrafluoroethylene), Plastik Saran (Polyvynilidine Chloride), LPDE, HPDE, dan PMMA (Polymethylmethacrylate).

Jenis plastik yang ditemukan di area laboratorium biologi dan Foodcourt UNY adalah jenis PET yang memiliki ciri-ciri bersifat jernih, kuat, tahan bahan kimia dan panas, serta mempunyai sifat elektrikal yang baik. Penggunaan PET banyak dimanfaatkan dalam bungkus botol minuman berkarbon, botol jus buah, peralatan tidur, dan fiber plastik serta material ini merupakan material utama dalam pembuatan prduk kantong kemasan makanan (Suminto, 2018).

Plastik merupakan limbah anorganik yang susah di olah namun dalam penggunaan pada kemasan makanan dapat bercampur dengan limbah organik yang memunculkan bau apalagi dengan negara berpendapatan menengah menghasilkan limbah sebesar 36\%-46\%. (Bhada Tata \& Hoorweg, 2012). Pengelolaan plastik ini menjadi tantangan dari PPM ini karena plastik yang tersedia tidak lah langsung dalam keadaan bersih, sehingga dibutuhkan pembersihan terlebih dahulu dan kemudian dikeringkan sebelum dipadatkan. Apalagi plastik yang ada di area Foodcourt UNY ini merupakan plastik bekas yang digunakan untuk bungkus makanan sehingga diplastik masih ada sisa-sisa makanan.

Plastik yang ada di Foodcourt UNY pun tidak dibuang pada tempatnya kebanyakan dibuang di meja makan ataupun di bawah pendopo. Permasalahan sampah ini tidak hanya terjadi di lingkungan Foodcourt UNY saja namun juga terjadi di Laboratorium Biologi FMIPA UNY. Dimana banyak mahasiswa yang membuang sampah sembarang seperti meninggalkan sampah di laci meja pada Ruang PPG 1 kemudian meninggalkan bekas botol minuman di Laboratorium Zoologi, Biologi Dasar, Lingkungan, Mikroskopi, dan lainlain. Peneliti disini mencoba untuk melihat kesadaran mahasiswa biologi dalam membuang sampah pada tempatnya dan sesuai arahan yang telah diberikan. Kegiatan dilakukan dengan menyediakan 3 kardus sampah yang diatasnya bertuliskan "Yuk Buang Sampah Plastik di sini." dengan satu kardus pada setiap lantai. Hasilnya adalah lebih dari $60 \%$ mahasiswa membuang sampah plastik sesuai arahan dan sisanya ada yang membuang sampah plastik namun dibarengi dengan bekas makanan, kemudian ada yang tidak membuang sampah plastik sesuai arahan.

Hanya sekitar 22\%-43\% saja sampah plastik di seluruh dunia yang dibuang ke tempat pembuangan sampah (Plastics, 2015). Kesadaran masyarakat terhadap lingkungan mendasari solusi terhadap suatu permasalahan lingkungan. Kesadaran terhadap lingkungan akan terbangun jika orang itu sudah mengenal sesuatu tersebut dengan baik (Handziko, 2017). Kesadaran membuang sampah sesuai aturan ini mengindikasikan bahwa kesadaran mahasiswa masih belum cukup mengenai aturan untuk dapat membuang sampah sesuai jenis dan tempatnya. Kebiasaan mahasiswa yang sering membawa sampah ke kelas menjadi hambatan dari PPM ini untuk mendapatkan hasil yang maksimal. Karena sampah plastik yang langsung dibawa ke kelas ini terkadang tidak dibawa lagi keluar sehingga laboratorium terdapat sampah plastik bekas bungkus makanan. Ini 
cukup mengurangi target dari kegiatan PPM yang ingin dicapai.

Sampah yang ada di Laboratorium Biologi dan Foodcourt UNY dibuang di Tempat Pembuangan Akhir yang ada di utara gedung Laboratorium FMIPA dan di belakang ruma makan Foodcourt UNY. Hal yang harus diperhatikan adalah setelah ditumpuk di TPA kemana sampah plastik tersebut akan dibuang kembali. Di Daerah Istimewa Yogyakarta yang menjadi pusat pembuangan sampah adalah di daerah TPA Piyungan. Berdasarkan data dari DKKP pada tahun 2005 didapatkan data bahwa produksi sampah perkotaan sebanyak 1.700 $\mathrm{m}^{3}$ per hari sedangkan yang dapat diangkut ke TPA Piyungan hanya sekitar $1.300 \mathrm{~m}^{3}$ per hari, sehingga terjadi penumpulan sampah sebanyak $400 \mathrm{~m}^{3}$ yang berada di lingkungan masyarakat. Data tahun 2005 ini saja sudah menunjukkan penumpukan sampah yang ada di salah satu TPA terbesar di Provinsi Daerah Istimewa Yogyakarta terlampau melewati volume sampah yang mampu ditampung. Sedangkan pada artikel yang di muat oleh Media Indonesia pada Tahun 2010 diketahui bahwa volume sampah negeri dan swasta dari 3 daerah yaitu Kota Yogyakarta, Kabupaten Sleman, dan Kabupaten Bantul yang dibuang di TPA Piyungan telah mencapai 110.654.545 Kg.

Jumlah sampah yang terlampu melewati daya tampung ini membutuhkan pengolahan yang baik apalagi sampah yang bagiannya adalah sampah plastik membutuhkan waktu penguraian yang sangat lama bahkan hingga mencapai ratusan tahun. Salah satu solusi untuk mengatasi ataupun mengurangi permasalahan ini adalah dengan Ecobrick. Eco-bricks adalah nama untuk botol PET yang diisi dengan beberapa bahan (Taaffe, J., O'Sullvan, S. Rahman,M.E., \& Pakrashi, 2014) yang bisa digunakan sebagai blok bangunan (Barajas \& Vera, 2016). Menurut Suminto, 2014, Ecobrick menjadi langkah dalam transisi ini dimana dapat menangkap semua siklus hara teknis dan bahan nonbiodegredable serta membuat langkah pertama dalam pembentukan desain cradleto-cradle dalam suatu produk.

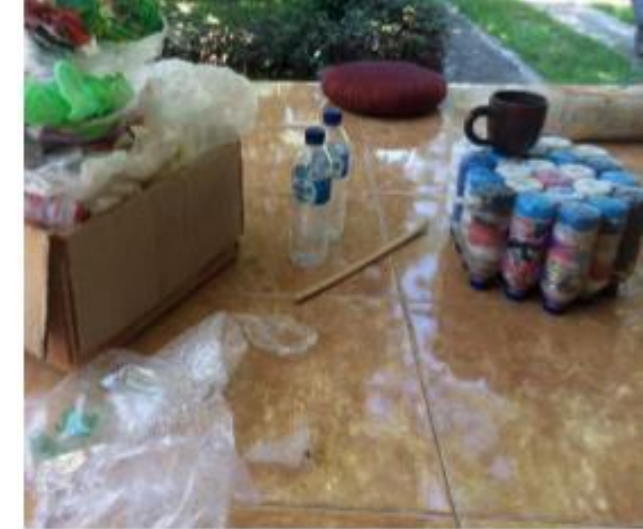

Gambar 1. Pemanfaatan sampah rumah tangga dalam pembuatan Ecobrick.

(Sumber foto : Sekartaji, 2016; dalam Suminto, 2017)

Ecobrick dapat dimanfaatkan sebagai solusi dalam mengurangi penggunaan sampah yang ada di Foodcourt UNY dan Laboratorium Biologi FMIPA UNY. Apalagi Ecobrick kini telah menjadi solusi dalam pengolahan bahan limbah anorganik terkompresi, khususnya plastik, busa, kemasan, dan cellophanes oleh masyarakat dan organisasi non-pemerintah (LSM) (Heisse, S., \& Arias, 2011).

Ada beberapa tahapan dalam membuat ecobrick yang tidak sulit dan hanya membutuhkan ketelatenan dalam proses pembuatannya yaitu sebagai berikut :

1. Botol plastik yang tidak terpakai bekas kemasan air minum dikumpulkan kemudian mencucinya lalu mengeringkannya

2. Mengumpulkan kemasan platik mie instan, bungkus makanan dan minuman, kantong kemasan, tas plastik dan sebagainnya. Plastik dipastikan bersih dari segala jenis makanan dan dalam keadaan kering serta tidak bercampur dengan jenis sampah lainnya.

3. Memasukkan sampah plastik ke dalam botol plastik yang telah disediakan lalu dipadatkan dengan menggunakan batang kayu. Pada tahap ini plastik bisa dipotong kecil ataupun dimasukkan secara langsung

4. Isi botol plastik tidak boleh bercampur dengan kertas, kaca , logam, benda-benda 
tajam dan bahan-bahan lainnya selain plastik. Kecuali jika peneliti atau pun masyarakat ingin menggunakan ecobrick yang berisi pasir.

5. Plastik yang dimasukkan ke dalam botol harus memenuhi seluruh ruangan sehingga tidak ada ruangan pada botol yang tersisa hal ini bertujuan agar kekuatan ecobrick tersebut maksimal.

6. Jika ingin membuat sesuatu dengan memanfaatkan konsep ecobrick maka dapat memnggunakan botol yang memiliki tinggi yang sama sehingga memudahkan dalam prosesnya

7. Jika menginginkan hasil yang berwarnawarni maka plastik-plastik kemasan yang disusun didalamnya diatur sedemikian rupa

8. Jika semua botol telah dipadatkan dan telah siap digunakan maka botol plastik tersebut disusun sesuai dengan produk yang ingin dibuat

9. Untuk merekatkan setiap botol menggunakan lem adesive/bahan semen.gibs supaya bisa merekat kuat.

Pada tahapan pembuatan ecobrick tahapan yang paling penting adalah pemadatannya sehingga didapatkan pondasi yang kokoh dan kuat. Dipadatkannya sampah plastik didalam botol berguna untuk meningkatkan jumlah pengisi karena ini akan mempengaruhi fisik dan sifat mekanik dari ecobrick itu sendiri yaitu seperti stabilitas volume, modulus elastis, dan perilaku pemulihan elastis-plastik (Antico, F. C., Wiener, M. J., Araya-letelier, G., \& Durán, 2017).

Gambar 2. Ecobrick yang diisi, (a) tetrapack, (b) metal, (c) PET, (d) paper \&

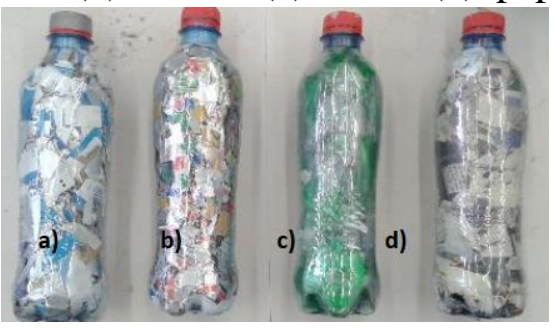

cardboard.

(Sumber foto : Antico, 2017)

Penggunaan tenaga manual memang menjadi tantangan bagi peneliti dalam membuat ecobrick karena kepadatan dari ecbrick tersebut akan mempengaruhi kepadatan dan kekuatannya. Namun, ecobrick ini dalam prosesnya harus terus dikontrol karena suhu akan berpengaruh terhadap kepadatan yang ada didalam botol ini sehingga dapat diketahui kebutuhan akan plastik berkelanjutannya. Suhu yang terlalu tinggi dapat berpengaruh terhadap ecobrick yaitu botol plastik menjadi lebih renggang sehingga ini dapat membuat kekokohan plastik menjadi berkurang.

Kebutuhan akan sampah plastik dalam jumlah besar juga menjadi hambatan bagi peneliti apalagi dalam penggunaan satu botol plastik membutuhkan banyak sampah plastik berbagai jenis hal ini dikarenakan sampah plastik dipadatkan dalam botol tersebut sehingga dibutuhkan banyak sampah plastik. Dalam membantu proses pengumpulan ini peneliti memanfaatkan media sosial dengan mencoba mempopulerkan tagar \#GaMakePlastik dan tagar inipun dinilai berhasil dalam membangun mindset mahasiswa untuk membuang sampah plastik pada tempatnya dan mengurangi penggunaan plastik dimasyarakat. Penggunaan tagar perlu dimasivekan lagi agar didapatkan hasil yang optimal dalam menciptakan kesadaran untuk tidak membuang dan menggunakan sampah plastik.

Proses ini merupakan suatu proses yang memang diharapkan bahwa masalahan mengetahui pengetahuan yang lebih komprehensif bahwa plastik memiliki masalah dalam hal daur ulang. Sehingga waktu yang dibutuhkan dalam proses daur ulang plastik bisa dimanfaatkan dengan menciptakan suatu produk baru. Kepedulian sekarang tentang pemanfaatan sampah yang sulit didaur ulang sangat dibutuhkan karena kepedulian di saat ini dapat berpengaruh di masa yang akan datang terhadap kelangsungan alam. Apalagi pembuatan ecobrick ini tidak membutuhkan biaya yang banyak, kemudian tidak membutuhkan skill khusus karena semua yang digunakan berangkat dari pemanfaatan barang seharihari. 
Ecobrick menjadi solusi dalam mengurung plastik dari peredarannya dilingkungan menjadi sesuatu yang lebih bernilai. Ecobrick juga menjadi contoh aksi dalam meningkatkan kesadaran mahasiswa dimana dengan menjadikan kebiasaan ecobricking ini dapat mengurangi penggunaan sampah plastik.

Kemudian, penggunaan ecobrick pada tahap pengumpulan sampah plastik ini dinilai berhasil terlihat dari kardus yang disediakan dilaboratorium biologi FMIPA UNY yang selalu penuh akan plastik dan mulai berkurangnya sampah yang ada di dalam ruangan laboratorium. Untuk pengembangan pada tahap berikutnya masih dibutuhkan alternatif pengumpulan sampah plastik yang lebih besar dan tim yang lebih banyak sehingga dapat menambah kebutuhan dalam membuat Ecobrick yang berguna bagi masyarakat Universitas Negeri Yogyakarta.

\section{Kesimpulan}

Berdasarkan penelitian yang telah dilakukan maka dapat disimpulkan bahwa pemanfaatan ecobrick dapat berguna dalam mengurangi jumlah sampah yang ada di Foodcourt UNY dan Laboratorium Biologi FMIPA UNY sehingga dapat menimbulkan kenyamanan dalam setiap aktivitas mulai dari aktivitas kampus ataupun kegiatan pembelajaran di kelas.

\section{Ucapan Terima Kasih}

Ucapan terima kasih diberikan kepada Dosen Ilmu Lingkungan Prof. I Gusti Putu Suryadarma, MS., Rio Christy Handziko, S.Pd.Si., M.Pd., yang sudah mengarahkan dan membimbing kami hingga berlangsungnya penelitian ini.

\section{Pustaka}

Antico, f. C., wiener, m. J., araya-letelier, g., \& durán, d. (2017). A construction time capsule for inorganic materials with potential of being recycled. In 2 nd international conference on bio-based building materials \& 1st conference on ecological valorisation of granular and fibrous materials. Eco-bricks, 1-5. Https://doi.org/10.7764/rdlc.16.3.518

Bengkulah, m. Taufiq f. (2017). Implementasi crs (corporate social responsibility) pt. Agung perdana dalam mengurangi dampak kerusakan lingkungan. (may).

Bhada tata, p., \& hoorweg, d. . (2012). What a waste?: a global review of solid waste management. The world bank, 15(3), 518-526.

Https://doi.org/10.7764/rdlc.16.3.518

Handziko, r. C. (2017). Wisata edukasi kampus melalui pelatihan pengamatan burung untuk siswa sekolah menengah atas. 1(2), 99-104.

Heisse, s., \& arias, v. (2011). Manual sistema constructivo pura vida. Manual sistema constructivo pura vida. Https://doi.org/10.7764/rdlc.16.3.518

Https://www.trijurnal.lemlit.trisakti.ac.id/ur banenvirotech/article/viem/1421/1234 diakses pada 6 mei 2019 pukul 18.33 wib.

Media indonesia. 2011.mengerem sampah bukan perkara mudah.

Plastics. (2015). An analysis of european plastics production,demand and waste data. The fact. Https://doi.org/10.7764/rdlc.16.3.518

Putra, h, p., \& y, y. (2010). Studi pemanfaatan sampah plastik menjadi produk dan jasa kreatif. Jurnal sains dan teknologi lingkungan, 2(1), 21- 31. 
Saldana, j. (2011). Fundamentals of qualitative research. Https://doi.org/10.23917/jiti.v17i2.6832

Sampah plastik jenis, p. P., dan menjadi bahan bakar minyak dan karakteristiknya untoro budi surono, p. P., \& ismanto, dan. (2016). Jurnal mekanika dan sistem termal (jmst). Jurnal mekanika dan sistem termal, 1(1), 32-37.

Sari, g. L. (2018). Kajian potensi pemanfaatan sampah plastik menjadi bahan bakar cair. Al-ard: jurnal teknik lingkungan, 3(1), 6-13. Https://doi.org/10.29080/alard.v3i1.255

Sirait, m. (2009). Sulap sampah plastik lunak jadi jutaan rupiah (vol. 3). Yogyakarta: b-frist.
Suminto, s. (2018). Ecobrick: solusi cerdas dan kreatif untuk mengatasi sampah plastik. Productum jurnal desain produk (pengetahuan dan perancangan produk), $3(1)$, 26. Https://doi.org/10.24821/productum.v3i 1.1735

Taaffe, j., o'sullvan, s. Rahman,m.e., \& pakrashi, m. (2014). Experimental characterisation of polyethylene terephthalate (pet) bottle eco-bricks. In materials \& design. Https://doi.org/10.7764/rdlc.16.3.518

Wahyudi, e., zultiniar, \& e, s. (2016). Pengolahan sampah plastik polipropilena (pp) menjadi bahan bakar minyak dengan metode perengkahan katalitik menggunakan katalis sintetis. Jurnal rekayasa kimia dan lingkungan, 11(1), 17-23. mei 2019 pukul 22.34 wib. 